\title{
Doğu Karadeniz'de Çay Tarımında Çalışan Gürcü İşçilerin Çalışma Koşulları Üzerine Gözlemler ${ }^{1}$
}

\section{Fevzi ENGIN ${ }^{2}$}

\section{Observations on Working Conditions Of Georgian Workers Who Work in Tea Agriculture}

\begin{tabular}{l} 
ARTICLE INFO \\
\hline Article History: \\
Date Submitted: 12.09 .2017 \\
Date Accepted: 11.10 .2017 \\
\hline JEL Classification: \\
J10 \\
J15 \\
Q10
\end{tabular}

Keywords:

Georgian Workers

Seasonal Tea Production Migrant Workers

\begin{abstract}
Not only in Turkey; but also in the World, a great number of the labouring man have been employed in the agricultural sector. Some peculiar conditions of agricultural sector cause a lot of problems two of which are economic migration and seasonal workers. In agricultural sector, the area which has the worst working conditions is seasonal working.
\end{abstract}

Tea agriculture provides temporary or seasonal working due to some imperative reasons such as hard working conditions, the necessity of harvesting the tea in the field in a definite period of time, effect of climate changes.

In this paper, migration problem in the sector analysed in terms of working conditions and relations of Georgian workers (food, job security, health and so on).The method used in the paper is observation and interview for the fieldwork.

This study is made based on personal observations following the interviews with workers, brokers, the owners of tea fields, the authorised officers in agricultural chambers and village headmen.

To sum up, the aim of the study is to find out the differences in working conditions of Georgian workers who work in tea agriculture in the Eastern Black Sea and to make same basic determinations about this issue.

In addition, considering the observation results, some suggestions for the future are made.

\footnotetext{
${ }^{1}$ Bu çalışma 22 Nisan 2017 tarihinde İstanbul'da gerçekleşen Uluslararası Sosyal Araştırmalar Kongresinde sunulmuş bildirinin düzeltilmiş halidir.

${ }^{2}$ Yrd. Doç. Dr., Abant İzzet Baysal Üniversitesi, İktisadi ve İdari Bilimler Fakültesi İktisat Bölümü Öğretim Üyesi, engin_f@ibu.edu.tr
} 


\section{Özet}

Günümüz ekonomilerinde çalışanların önemli bölümü tarım kesiminde istihdam edilmektedir. Ülkemizde de durum aynıdır. Tarım kesiminin kendine özgü koşulları nedeniyle birçok sorunlar ortaya çıkarmakta, bu sorunların başında ekonomik göç ve mevsimlik işçi sorunu gelmektedir. Tarım kesiminde çalışma koşullarının en kötü olduğu çalışma biçimim mevsimlik işçiliktir.

Çay tarımı; çalışma koşullarının zorluğu, ürünün belli bir sürede toplanma gerekliliği, çalışmanın büyük kısmının arazide gerçekleşmesi, iklim koşullarından etkilenme gibi zorunlu nedenlerle geçici ve mevsimlik işçi istihdamını beraberinde getirmektedir.

$\mathrm{Bu}$ çalışmada, sektördeki göç sorunu çay hasadı örneği üzerinden Gürcü işçilerin çalışma koşullarını ve iş ilişkilerini -ücret, barınma, yemek, iş güvenliği, sağlık- gibi sorunlar açışında incelenmeye çalışılacaktır.

Araştırmada kullanılan yöntem, gözlem ve alan araştırması olarak görüşme tekniğinin kullanılmasıyla yapılmıştır. Çalışma 2016 yılında Doğu Karadeniz Bölgesinde çalışan Gürcü işçiler, aracılar, çay bahçesi sahipleri, ziraat odası yetkilileri ve muhtarlarla gerçekleştirilen görüşmeler ile kişisel gözleme dayalı olarak yapılmıştır.

Sonuç olarak; Doğu Karadeniz' de çay tarımında çalışan Gürcü işçilere ilişkin çalışma koşullarındaki farklılıkları ortaya koymak ve bazı temel saptamalar yapmaktır. Ayrıca elde edilen gözlem sonuçlarından hareket ederek geleceğe ilişkin belirli önerilerde bulunulacaktır.

Anahtar Kelimeler: Gürcü İşçiler, Mevsimlik İşçi, Çay Üretimi, Göçmen İşçi

\section{GíRIȘ}

Dünya'da ve ülkemizde nüfusun belli bir kesimi tarım kesiminde çalışmaktadır. Tarım kesiminin kendine özgü koşulları nedeniyle; çalışmanın dış mekânda gerçekleşmesi, iklim koşullarından etkilenme, üretim ve hasadın belli bir süre içinde yapılması, çalışma koşullarının 
ağır olması nedeniyle geçici iş ilişkisini beraberinde getirmektedir(Kablay, 2016:281). Yine bu tip çalışmada çalışanların büyük bir kısmı mevsimlik işçi olarak çalışmaya gelmesi çalışma ve yaşam koşulları açısından önemli sorunlar doğurmaktadır.

Dünya'da olduğu gibi Türkiye'de de mevsimlik tarımsal üretimde yabancı göçmen işçi gücü istihdamı yaygın biçimde görülmektedir(Kalkınma Ajansı, 2016:14). Türkiye'de tarım alanında temel sorunlardan birisi iş gücü arz ve talep arasındaki dengesizliktir. Bu dengesizlik mevsimlik tarım işçiliği yoluyla karşılanmaktadır. Doğu Karadeniz'de çay tarımında işçi olarak çalışan göçmen grubunun en önemlisi Gürcistan'dan Türkiye'ye gelen Gürcü işçiler oluşturmaktadır.

$\mathrm{Bu}$ çalışmada, sektördeki göç sorunu çay hasadı örneği üzerinden Gürcü işçilerin çalışma koşullarını ve iş ilişkilerini; Ücretler, Barınma Koşulları, İşçi Sağlı̆̆ı ver İş Güvenliğii, Çalışma Süreleri, Aracılık gibi temel sorunlar açısından incelemeyi amaçlamaktadır.

Araştırmada kullanılan yöntem, gözlem ve alan araştırması olarak 2016 yılında Temmuz-Ağustos ayları arasında Rize ve Artvin illerinde görüşme tekniğinin kullanılmasıyla yapılmıştır. Görüşme yapılan kişi ve kurumlar ise şunlardır. Bölgede çalışan Gürcü İşçiler, aracılar, çay tarla/bahçe sahipleri, Ziraat Odası Temsilcileri, muhtarlar ve kişisel gözleme dayanmaktadır.

\section{MEVCUT DURUM}

2015 ÇAY-KUR İstatistik Verilerine göre 762.000(dekar) çaylık alanda, 210.000 üretici tarafından 1,36 Milyon yaş çay üretimi gerçekleştirilmiştir. Bu üretimin yüzde 56's1 ÇAYKUR'un 46 fabrikasında, yüzde 44'ü özel sektörün 151 fabrikasında işlenmiştir. Çay üretiminin en önemli aşaması, çay ürünün toplanması ve bu toplanana ürünün çay işleme fabrikasına taşınması aşamasıdır. Çay bitkisi yılda üç kez toplanarak hasadı yapılan bir üründür. Bu toplama ayları Mayıs-Temmuz-Eylül aylarıdır.

Çay ürününün toplanması ve fabrikaya taşınması aşaması çay üretiminin en fazla en yoğun istihdam gerektiren aşamasıdır. 
Doğu Karadeniz Bölgesi’nde çay üretimi ve bu üretimin iş gücü ihtiyacını etkileyen iki temel dinamik bulunmaktadır.(Kalkınma Atölyesi, 2016(a):112). Birincisi, bölgenin hem yurtdışı hem de yurtiçi göç veren bir bölge olması. İkincisi, toprak mülkiyetinde ortaya çıkan değişimlerdir. Toprakların miras yoluyla küçülmesi, tarımsal üretimdeki dalgalanmalar. Devletin tarıma yönelik uyguladığı politikalar nedeniyle bölge halkının gelirlerinde önemli düşüşler yaşanmıştır. Yaşanan yoğun göç, yaşlanan kırsal nüfus, mirasla küçülen araziler, kültürel nedenlerle arazi bütünleşmesinin gerçekleşmemesi, çay ürününün tek gelir kaynağ 1 olmaktan çıkması, ücretli tarım işçiliğine olan ihtiyacı arttırmaktadır(Kalkınma Atölyesi, 2016(a):185).

\section{2. ÇAY ÜRETIMINDE MEVSIMLIK IŞ GÜCÜ BİÇIMLERİ VE YAŞANAN SORUNLAR}

\section{1. Çay Üretimde Yaşanan İşgücü Biçimleri}

Çay üretiminde meydana gelen sosyo-ekonomik dönüşüm, çay üretiminin büyük bir kısmının dönüşüm, çay üretiminin büyük bir kısmının ücretli işçilik yapılması sonucunu doğurmuştur.

Yaş çay yaprağının toplanmasında beş farklı toplama biçiminin bulunduğu belirtilmektedir(ÇAYSİAD, 2015:10). Kendi çayını kendisi toplayanlar mahalli işçiler, yarıcılar, mevsimlik gezici işçiler ve yabancı işçilerdir. Çalışmanın konusu bu çalışma biçimleri içinde yabancı göçmen işçiler ve bunların yarattı̆̆ 1 sorunların tespiti üzerinde yapılacaktır. Yabancı göçmen işçilerin büyük bir çoğunluğu Gürcistan'dan gelen ve kayıt dışı çalışan işçilerden oluşmaktadır.

Gürcistan'ın coğrafi olarak Türkiye’ye yakın olması, bölgedeki Gürcü Nüfusun varlığı, iki ülke arasında karşılıklı ilişkileri geliştirmek adına uygulanan vize rejiminin sonuçları göç hareketini büyük ölçüde artırmıştır. 
Tablo 1: Gürcistan'dan Türkiye'ye Giriş ve Çıkışlar(2010-2015)

\begin{tabular}{|l|l|l|}
\hline$\underline{\text { YILLAR }}$ & GiRIS & CIIKIS \\
\hline $\mathbf{2 0 1 0}$ & 1.109 .615 & 1.094 .619 \\
\hline $\mathbf{2 0 1 1}$ & 1.149 .362 & 1.138 .870 \\
\hline $\mathbf{2 0 1 2}$ & 1.404 .882 & 1.393 .971 \\
\hline $\mathbf{2 0 1 3}$ & 1.769 .447 & 1.755 .484 \\
\hline $\mathbf{2 0 1 4}$ & 1.755 .289 & 1.736 .134 \\
\hline $\mathbf{2 0 1 5}$ & 1.911 .832 & 1.908 .008 \\
\hline
\end{tabular}

Kaynak: Kültür ve Turizm Bakanlığı, sınır giriş çıkış istatistikleri http//yigm.kulturturizm.gov.tr(ET:20 Kasım 2016)

Çizelge birde görüldüğü gibi 2010 yılından artarak devam eden ve 2015 yılında yaklaşık iki milyona yakın Gürcü’nün Türkiye’ye giriş yaptı̆̆g ve farklı iş gücü piyasasına katıldıklarına ilişkin bulgular sunmaktadır. Mevsimlik tarım işinde çalışan göçmenlere ilişkin yapılan araştırmalarda Gürcü işçilerin hem fındık hem çay tarımında çalıştıklarını göstermektedir (ÇAYSİAD, 2015, CİĞERCİ, Ulukan ve Ulukan 2015, Karaman ve Y1lmaz 2011).

Gürcülerin büyük çoğunluğu Türkiye'ye Sarp Sınır Kapısını kullanarak girmekte ve yüzde 51'i çalışma izni olmadan sadece vize süresince Türkiye'de kalmakta olduğunu belirtmiştir(ERGEM, 2014:154 Aktaran Kalkınma Ajans1). Çay toplamak için gelen Gürcü işçilerin kayıtları olmadığı için çay işinde çalışanları tespit etmek zordur. Kayıt dışı çay toplama ve taşıma işlerinde çalışanların 2016 yılında yaklaşık 16 bin işçinin çalıştığını belirtmişlerdir(Fındıklı Çay Üreticileri Başkanlığıyla yapılan görüşme).

Sarp Sınır Kapısı'ndan yapılan girişlerin aylık olarak incelendiğinde, çay toplama dönemlerinde girişlerin oldukça yükseldiğini göstermektedir. 
Tablo 2: Ülkemize Giriş Yapan Gürcü Yolcu Sayıları(2015-2016)

\begin{tabular}{|c|c|c|c|}
\hline AYLAR & $\underline{2014}$ & $\underline{2015}$ & $\underline{2016}$ \\
\hline OCAK & 103.8 & 108.6 & ------- \\
\hline ŞUBAT & 102.327 & 108.615 & 144.046 \\
\hline MART & 127.463 & 126.230 & 158.233 \\
\hline NISAN & 140.514 & 138.605 & 172.603 \\
\hline MAYIS & 183.970 & 197.713 & 217.666 \\
\hline HAZİRAN & 171.823 & 166.296 & 180.580 \\
\hline TEMMUZ & 197.226 & 223.970 & 195.805 \\
\hline AĞUSTOS & 244.252 & 236.688 & 202.328 \\
\hline EYLÜL & 176.986 & 223.845 & 210.209 \\
\hline EKİM & 156.284 & 171.876 & ------ \\
\hline KASIM & 134.8 & 160.917 & ------ \\
\hline ARALIK & 132.519 & ------- & ------ \\
\hline
\end{tabular}

Kaynak: KÜLTÜR VE Turizm Bakanlığı, htpp/yigm.kulturturizm.gov.tr Sınır Giriş-Çıkış İstatistikleri (ET 20 Ekim 2016)

Çizelge ikide görüldüğü gibi tarımsal ürünlerde hasat toplama aylarının başlamasıyla birlikte özellikle çay tarımı ile ilgili Mayıs, Temmuz, Eylül yükselmekte diğer aylarda azaldığı görülmektedir. Ağustos ayının en yüksek olmasının nedeni çay hasadı ile fındık hasat zamanının örtüşmesinden kaynaklanmaktadır. Özellikle Mayıs-Temmuz aylarında başlayan ve toplanan çay hasadının Gürcü işçilerin sınırdan girişini artıran etkenlerden biri olduğu söylenebilir. Mayıs sonundan itibaren üç hasat döneminde biçilen çay ürünü Gürcülere sağlanan üç aylık vize ile tam olarak örtüşmesi büyük ölçüde çalışma kolaylığı sağlamaktadır. 
Ayrıca 31 Mayıs 2011 tarihinde imzalanan protokol gereğince, iki ülke vatandaşları, birbirlerinin ülkelerine pasaporta ihtiyaç duymadan kimlik kartlarıyla girebilmektedir(Kalkınma Atölyesi 2016(a): 85).

Türkiye'de önemli bir Gürcü nüfusun bulunması ayrıca uygulanan liberal vize rejiminin avantajlarını kullanarak mobiliteyi arttırmaktadır.

\subsection{Gürcü Göçmen İşçilerin Yaşadığı Sorunlar}

Tarım kesiminde mevsimlik işçilik çalışma biçimleri arasında en kötü koşulların olduğu kesimdir. Bu koşullar mevsimlik işçi çalıştırmayı zorunlu kılmakta göçle birlikte mevsimlik göçmen işçi çalıştırmayı da beraberinde getirmektedir.

Çay üretimi çalışma koşullarının ağır olması, “özellikle yaş çay toplama işinin” dış mekânda gerçekleşmesi, iklim koşullarından aşırı düzeyde etkilenme, ürünün belli sürede toplanma zorunluluğu gibi nedenlerle yoğun emek ve geçici iş ilişkisini beraberinde getirmektedir.

Bu çalışmada çay tarımında çalışan göçmen Gürcü işçilerin iş ilişkilerine saptanan, Çalışma Koşulları, Aracılık ve Ücretlerinin Ödenmesi, İşçi Sağlı̆̆ ve İş Güvenliği, Barınma ve Beslenme Koşulları açısından ortaya çıkardığı sorunların incelenmesine dayalıdır.

\subsection{1. Çalışma Koşulları}

Mevsimlik tarım işçilerinde çalışma koşulları içinde en önemli sorunların başında çalışma süresi gelmektedir. Çay üretiminde çalışma süresi hasat zamanıyla sınırlıdır. Çayda hasat zamanı yılda üç kez (Mayıs, Temmuz, Eylül) gerçekleştirilir. Çay biçme işlemi güz aydınlanınca başlayıp hava kararıncaya kadar devam eden süredir. Bu çalışma süresi günlük 10-12 saate denk düşmektedir. Gürcü işçilerle yapılan görüşmede alım yerine taşınması ve satış1 işçiye ait olduğundan bazı günlerde çalışma süresini günlük 16-17 saate uzadığını belirtmişlerdir. Ayrıca çalışma alanlarının dış mekân olması ve arazilerin çoğunun dik ve meyilli olması çay biçme işlemini yoğun ve fiziki olarak yorucu bir faaliyet haline getirmektedir. Çay bahçelerinin yerleşim alanından uzak olması nedeniyle işçilerin günlük 
ihtiyaçlarını bahçede gidermek zorunda olmasıdır. Yemek yeme, dinlenme, tuvalet ve benzeri ihtiyaçların tümü çay bahçelerinde giderilmektedir. Gürcü işçilerle yapılan görüşmelerde özellikle kadın işçiler tuvalet ihtiyaçlarını açık alanda yapmak istemediklerini, zor durumda kalmadıkları sürece yapmamayı tercih ettiklerini belirtmişlerdir.

\subsubsection{Gürcü Göçmen İşçilere Erişim ve Ücretlerinin Ödenmesi}

Tarım sektöründeki mevsimlik çalışma rejiminin en önemli unsuru Aracılık kurumudur. Bazı aracılar bölgeye göre işçi simsarı, elçi, dayı başı, çavuş gibi isimlerle anılır. İşçi ve işverenin haklarını savunduklarından iki kesim arasında köprü görevi yaparlar(Yıldırak vd, 2004:41-42 Aktaran, Karaman ve Y1lmaz 2011:217).

Aracılık; "tarımsal işlerin yoğunlaştığı mevsimlerde işverene karşı işçi, işçilere karş1 işveren adına ilişki kurarak tarımda emek arz-talep dengesini sağlamaya" çalışan bir kurum olarak tanımlanmaktadır(Kablay, 2016:292). Yaptığımız gözlem ve görüşmelerde hem kendi grupları içinde, hem de Türk vatandaşlarına aracılık yaptıkları tespit edilmiştir. Bu iş ilişkisi yasal bir sözleşmeye dayanmadan karşılıklı güvene dayalı işlemektedir. Anlaşmazlık durumlarında hukuki olarak çözülebilecek hiçbir durum mevcut değildir.

Aracılar ihtiyaç duyulduğunda işçilere kalacak yer ayarladığını ve ulaşım hizmetinin kendisi tarafından karşılandığını belirtmiştir. Gürcistan sınırına yakın olan bölgelerde günübirlik çalışma şeklinde "amele pazarı" diye nitelenen kahve ya da çay bahçelerinde iş ilişskisi gerçekleştirmektedir.

Aracılar hukuki düzenlemelere göre yalnızca işçi başına yevmiyenin genellikle yüzde onu kadar veya toplanan ürün miktarının birim toplama ücretinin yüzde onu veya çalışma yapılan alan miktarına(dekar başına) göre belirlenen ücretin yüzde onu kadar ücret alırlar. Eğer aracılar, ulaşım, kalacak yer ve yemek gibi hizmetleri üstlenmiş ise bu oran çok daha artmaktadır.

Bunlara ek olarak Gürcü göçmen işçilerin Türkiye'de var olan akrabalık ilişkilerini de aracı kurum olarak değerlendirmektedirler. Mevsimlik tarım işçilerinin ücret ödemeleri en tartışmalı konuların başında gelmektedir. Ücretler yapılan iş, bölgeye, iş gücünün niteliğine 
göre değişmekle beraber, illerde ve ilçelerde mülki amirler (Vali, Kaymakamlık) başkanlığında Ziraat Odası temsilcilerinin de bulunduğu komisyon Tarafından belirlenip ilan edilmektedir. Yaptığımız görüşmelerde ücret ödemelerinde bu tespite uyulmadı̆̆ gibi taban ücretin saptanması açısından da bir belirleyicilik sağlanmamaktadır.

Rize'de İzleme Komitesi olarak kurulan bir komisyon çay toplama ücretlerini günlük 70 TL olarak belirlemesine karşılık "Çay Üreticilerin Dikkatine: 2015 yılı çay toplama işçiliği için Rize ili ve ilçelerinde üretici temsilcileri, kurumları, muhtarları, dernek başkanları, ziraat odaları ve bazı kurum yetkilileri ile yapılan bütün çalışmaların sonunda mutabık kalınan azami miktarı tonu 250 TL, yola kadar taşıma azami dahi tonu 275 TL, gündelik yevmiye 70,00 TL ve saat ücreti 7,00 TL olarak belirlenmiştir. Ülkemiz gerçeğinde bütün tarım işçiliği miktarının belirlenme usulü ile çay tarım işçiliğinde de bu şekil belirlenmiş ve bundan böyle de işçilik bedeli böyle belirlenecektir.1- Bu mutabık genelgeye uymayanlar veya bunu bozanlar. Veballeri üzerinde taşıyacaktır. 2-Kamuoyunda her türlü şekilde deşifre edilecekler. 3- Kanuni müeyyideye uğratılacaklar. 4- Konu bilinmeyen kişilerce köy ve mahallerde takip edilecek bir sonraki sürgünde işçi çalıştırdıkları zaman kolluk kuvvetlerinde kanuni sorumluluk istenecektir. (İzleme Komitesi)”, 2015 yılından bölgede çay hasadında günlük yevmiyeler 90100 TL arasında belirlenmiş, bunlara ek olarak öğle yemeği, sigara, telefon kontörü gibi ayrı ödemelerde sağlamıştır. 2016 yılı ücret ödemelerinde çay tarlaların konumuna göre değişmekle beraber, ton başına 320-350 TL arasında değişmekte günlük yevmiyeler ise 90-110 TL arasında değişmektedir. Ödemeler genelde Türk Lirası üzerinden yapılmaktadır. Tüm bu iş ilişkileri yasal olmayan karşılıklı güvene dayalı geleneksel enformel ilişkiler ağıyla belirlenmektedir. Aracılar, çalışan işçiler ve çalıştıran tarla sahipleri ile yapılan görüşmelerde aracılar ücretlerini tam ve zamanında alamamaktan, işçiler emeğinin karşılığını alamamaktan, arazi sahipleri(işverenler) de çalışanlar ve aracılar üzerinde yasal bir sözleşmeye dayalı yaptırım uygulayamamaktan yakınmışlardır.

Ücretlerle ilgili gözlemlenen bir diğer saptama ise yerli işçi ücretlerinin Gürcü göçmen işçilere göre en az yüzde 10 ile yüzde 20 arasında değişen bir oranda daha fazla olmasıdır.

\subsubsection{Gürcü Göçmen İşçilerde İş̧i Sağlığı ve İş güvenliği}


Yaş çay toplama hasadının tümüyle dış mekânda gerçekleştirilmesi, çay toplama arazilerinin yerleşim yerlerinden uzak olması gibi nedenlerden dolayı İşçi Sağlığı ve İş Güvenliği açısından birçok tehlikeyi barındırmaktadır. Çalışma alanında İşçi Sağlığı ve İş Güvenliği önlemleri yok denecek kadar az olup çalışanlar ne gibi risklerle karşı karşıya olduklarının farkında değildir. Mevsimlik tarım işlerinde istihdam edilen Gürcü işçilerin en önemli sorunu kayıtlı ve izinli çalışmadıkları için sosyal güvenlik haklarının olmamasıdır. Çalışma esnasında yaşanan sağlık sorunları ve iş kazaları durumunda işçiler bu riskleri kendileri üstlenmek durumunda kalmakta ve kendi olanaklarıyla karşılamaktadır. Bunların karşısında herhangi bir hak talebinde bulunmaya sahip değillerdir. Hukuk sistemimiz içinde mevsimlik işçilere özgü bir yasal düzenleme bulunmamaktadır(Toprak; 2015:5). Sadece çalışma koşulları düzenleyen Başbakanlık Genelgeleri bulunmakta, genelgede yapılması gereken faaliyetlerin çoğu yerine getirilmediği gibi, taraflarda bu düzenlemelerden haberdar olmadıklarını belirmişlerdir. Çay üretim bölgesinde iklim koşullarının nemli ve yağışlı olması, ürün hasadının açık alanda yapılması nedeniyle bunlara ilişkin koruyucu önlemeleri işçiler kendi olanaklarıyla karş1lamaktadır.

\subsubsection{Gürcü Göçmen İşçilerde Barınma ve Beslenme Koşulları}

Göçmen işçiler daha çok bahçe sahiplerinin kendilerine sağladığı mekânlarda konaklamakta ya da kendilerinin sağladığı konutlarda toplu olarak kalmaktadır. Yakın bölgelerde çalışan işçiler ise günübirlik çalıştıkları için akşam evlerine dönme olanakları bulunmaktadır. Bazı durumlarda bahçe kenarlarına kurdukları derme çatma çadırlarda konaklamaktadırlar. İşçilerin bahçeye yakın yerde konaklamaları hem bahçe sahipleri hem de çalışanlar açısında kolaylık sağlamaktadır. Çünkü ulaşım maliyetleri ve zaman açısından büyük kolaylık sağlamaktadır. Bazen de bir köye bir toplama dönemi kalıp bütün köydeki çayı biçtikleri belirtilmiştir.

Gürcü işçiler beslenme ihtiyaçlarını iki şekilde karşılamaktadır. Birincisi eğer yapılan ücret anlaşması yemek ve barınma dahil ise işverene ait olup üç öğün yemek dikkate alınarak ücret belirlenmektedir. İkincisi ise yemek ve konaklama ücretlere dahil ise işçiler yemeklerini toplu olarak yapmakta ve yemektedirler. Çalışma yerleri dış mekanda ve yerleşim yerine yerlerine uzak özellikle öğle yemeği, dinlenme, tuvalet ihtiyaçlarının tümü bahçelerde 
giderilmektedir. $\mathrm{Bu}$ durum hijyen koşullarında uzak ve yemeklerin korunması için buzdolabı olanağının bulunmaması zaman zaman gıda zehirlenmesine bağlı sağlık sorunları yaşanmaktadır.

\section{SONUÇ}

Doğu Karadeniz Bölgesi’nde yaşanan toplumsal değişime bağlı olarak çay üretiminde kullanılan işgücü ihtiyacı artmış ve bu gün çay hasadının yarısı yaklaşık 12 bin Gürcü işçi tarafindan yapılır hale gelmiştir.

Çalışan Gürcü işçilerin tümüne yakını kaçak ve kayıt dışı çalıştıkları için ücret, işçi ve iş sağlığı güvenliği, barınma ve beslenme koşulları açısından önemli sorunlar yaşanmaktadır. Özellikle bu koşulların yabancı Gürcü işçiler açısından bakıldığında bu olumsuzlukların daha da yetersiz olduğu dikkat çekmektedir. Ücretlerin düşük olması, iş güvenliğinin yeterince sağlanmaması, barınma ve beslenme koşullarının yetersizliği bunların başında gelmektedir.

Çay üretiminde çalıştırılan Gürcü işçilerin çalıştırılmasından kaynaklanan sorunların giderilmesi için: Tarımda sosyal güvenlik kapsamında olmadan bu konumdaki işçilerin İş Kanunu'nun kapsamına dahil edilmesi onların çalıştıkları süre içinde iş kazası, meslek hastalığı veya ölüm hallerinde yararlanacak biçimde sigorta sistemine dahil edilmelidir(Kalkınma Ajans1,2016b:23).

Çalışan işçilerin, işveren ve aracılar arasındaki ilişkiler bu gün geleneksel güven temeline dayalı enformel ilişkiler biçiminde gerçekleştirilmektedir. Bu ilişskiler ağı sömürüyü derinleştiren mekanizmaları güçlendirmektedir.

Gürcü işçiler sadece çalışma alanında değil yaşam alanlarında da pek çok sorun yaşamaktadır. Özellikle kadın çalışan işçiler, insan ticaretine maruz kalacak durumla karşı karşıya kalmaktadırlar. Ayrıca kadınların çocuk bakımı, barınma ve çalışma koşullarının iyileştirilmesi, yemek ve tuvalet gibi faaliyetlerin daha uygun ortamlarda gerçekleştirilmesi için gerekli düzenlemeler yapılmalıdır. 
Sonuç olarak Türkiye'de yabancı göçmen işçiler Gürcü işçilerle sınırlı değildir. Türkiye'de yabancı göçmen işçilerin mevcut durumu ve yarattığı ciddi ilişkiler ağı ve ortaya çıkardığı sorunlar saptanmalı ve bu konuda gerekli yasal ve kurumsal düzenlemeler ivedilikle yapılmalıdır. Mevcut olan geçici çözümler ve düzenlemeler bu sorunların giderilmesinde yetersiz kalmaktadır. Özetle yabancı göçmen işçilerin durumu hakkında daha ayrıntılı bilimsel çalışmalar yaparak karşılaştıkları tüm hak ihlallerine karşı bir an önce yasal ve kurumsal düzenlemelerin yapılması gerekmektedir.

\section{Kaynakça}

Ciğerci, U. N ve Ulukan, U. (2011). Kriz ve Göç Türkiye Gürcistan Arası Nüfus Hareketleri Üzerinde Bir Tartışma; Küresel Bunalım ve Karadeniz Bölgesi Ekonomileri, Ed. (E. Akbostancı ve O. Erdoğdu). Türkiye Ekonomi Kurumu, İmaj Yayınları, Ankara

ÇAYSİAD, (2015) 2014 Yılı Çay Sektörünün Durumu Sorunları ve Çözüm Önerileri, http://www.caysiad.org.tr (4.09.2016)

ÇAYSİAD,(2015) 2014 Y1lı Çay Bölgesi İstihdam Raporu http://www.caysiad.org.tr $(8.10 .2016)$

ERGEM - Enhancing the Role of Georgian Migrants at Home Project (2014) Georgian Diaspora and Migrant Communitied in Germany, Greece anda Turkey: Transnational realities and ties with Georgia, international Centre for Migration Policy Development, Vienna-Austria.

Gümüş, E. (2016), Çay Sektöründe Yabancı İşçi Sorunu.(VESTEL.ARGE) http://www.evrengumus.@vestel.com.tr (12.11.2016)

Kablay, S. (2016), Fındık Bahçesinde İşçi Olmak: Ordu ve Giresun İllerinde Mevsimlik Tarım İşçilerinin Çalışma Koşulları (Der) Deniz Yıldırım-Evren Haspolat, Değişen Karadeniz'i Anlamak. Phoenix Yayınevi. Ankara, 281-308

Kalkınma Ajansı(2016), Türkiye’ de Mevsimlik Tarımsal Üretimde Yabancı Göçmen İşçiler Mevcut Durum Raporu, Ankara 
Kalkınma Ajansı(2016b), Türkiye'de Mevsimlik Tarımsal Üretimde Yabancı Göçmen İşçiler, Politika Önerileri, Ankara

Karaman, K. Yılmaz, A. Y. (2011), Mevsimlik Tarım İşçileri ve Enformel İlişsiler Ağı: Giresun'da Çalışa, Mevsimlik Tarım İşçileri Üzerine Bir Araştırma, ZFWT.VOL.3.NO.1(2011 sh.(2011-226))

Stıftung, F.E. MIGA(2012): Tarımda Mevsimlik İşçi Göçü Türkiye Durumu Özeti(Mevsimlik İşçi Göçü Türkiye Durum Özeti), İstanbul

Toprak, F. (2015) “Mevsimlik Tarım İşçileri” T.B.M.M Araştırma Merkezi Ocak Sosyal Politika Bölümü

http://yigm.kuturturizm.gov.tr ( 20.11.2016)

http://www.tuik.gov.tr (15.11.2016)

http://www.iskur.gov.tr (10.10.2016)

http://www.caykur.gov.tr İstatistik Bülten 2015, (20.10.2016) 